J. Dairy Sci. 92:6197-6201

doi:10.3168/jds.2008-1519

(c) American Dairy Science Association, 2009.

\title{
Short communication: Polymorphism of casein cluster genes in Czech local goat breeds
}

\author{
Z. Sztankóová, ${ }^{*}$ V. Mátlová, ${ }^{*}$ J. Kysel’ová, ${ }^{* 1}$ O. M. Jandurová,† J. Říha,ł and C. Senese§ \\ *Institute of Animal Science, 10400 Prague, Czech Republic \\ †Research Institute of Crop Production, Research Station of Viticulture, 26718 Karlstejn, Czech Republic \\ $\ddagger$ Mendel University of Agriculture and Forestry, Agronomy Faculty, 61300 Brno, Czech Republic \\ $\S$ Dipartimento di Scienze delle Produzioni Animali, Università degli Studi della Basilicata, 85100 Potenza, Italy
}

\begin{abstract}
The 4 casein loci were evaluated as haplotypes in 2 dairy goat breeds kept in the Czech Republic. Analysis of 41 White Shorthaired (WSH) trio families and 44 Brown Shorthaired (BSH) trio families revealed 14 and 20 haplotypes, respectively. Various genomic techniques were used to type the casein loci. Twenty-two different combinations of these alleles (casein haplotypes, in the order CSN1S1-CSN2-CSN1S2-CSN3) were found. Only 5 haplotypes in the WSH breed and 6 haplotypes in the BSH breed occurred at frequencies $>0.05$. For the WSH breed, the most common haplotype was FCFB (0.260), whereas for the BSH breed, the most common haplotype was FCFA (0.217). The information on the haplotype variability in both breeds could be used in breeding programs aimed at preserving biodiversity or selecting animals for specific protein production and cheesemaking.
\end{abstract}

Key words: goat, casein haplotype, genetic polymorphism

In goat milk, the most abundant proteins are $\alpha_{\mathrm{S1}^{-}}, \beta-$, $\alpha_{\mathrm{S2}^{-}}$, and $\kappa$-casein, which constitute approximately $80 \%$ of the milk proteins. Genes coding for these proteins cover an area of approximately $250 \mathrm{~kb}$ of the genomic DNA, all located on chromosome 6 (Threadgill and Womack, 1990; Hayes et al., 1993; Rijnkels et al., 1997). Tight linkage of the casein loci permits the use of the allelic sequence on a single chromosome (haplotype; Velmala et al., 1995) as a multilocus genotype showing breed specificity and giving higher polymorphic information content (PIC) compared with individual loci (Lien and Rogne, 1993; Velmala et al., 1995).

Investigation of casein haplotypes started around 30 years ago (Hinnes et al., 1977) and an extensive research interest still exists because of the relationship with milk composition (Boettcher et al., 2004; Sacchi et al., 2005; Caroli et al., 2006), breed biodiversity and variability,

Received July 3, 2008

Accepted September 15, 2009.

${ }^{1}$ Corresponding author: kyselova.jitka@vuzv.cz mutual relation between breeds, finding an ancestral haplotype, and breeding strategies (Lien and Rogne, 1993; Velmala et al., 1995; Sacchi et al., 2005; Caroli et al., 2006, 2007). Typing of haplotypes and subsequent selection could be used to increase the rate of genetic gain in closed nucleus breeding programs, as Meuwissen and Goddard (1996) have presented. The investigation casein haplotypes of local goat breeds that are included in the conservation program of genetic resources could contribute to their characterization and genetic diversity preservation. The haplotype coding for $B A A B$ protein variants (in the order CSN1S1-CSN2-CSN1S2-CSN3) is considered the ancestral haplotype in goat species (Caroli et al., 2006).

Caroli et al. (2007) have also postulated that the casein haplotypes with a high frequency of highly expressed alleles might already be selected because of their advantages in nutrition. Haplotypes providing greater protein and casein contents increase the nutritive value of milk, thus being more favorable for the growth and survival of young goats and humans consuming the milk

The aim of this work was to investigate the frequencies of different allelic combinations of genes in the casein complex in 2 Czech dairy goat breeds, White Shorthaired (WSH) and Brown Shorthaired (BSH), and to evaluate casein haplotype variability within and between these breeds. This information could be used in selection and conservation programs for keeping both breeds.

The WSH and BSH goats are Czech national breeds raised mainly for cheese production. They are characterized by high milk yield, good fertility, and early maturity (Oklahoma State University). The breeds were developed as separate populations starting from a common base of local rustic-type goats. In 1997, both breeds were enrolled as "potentially endangered" in the National Program for Conservation of Genetic Resources. Under this program, a virtual breeding nucleus of about 800 and 1,800 purebred dams (BSH and WSH, respectively) kept by individual breeders was created. 
Table 1. Analyses applied to the DNA samples for genotyping

\begin{tabular}{llll}
\hline Locus & Method & Typed alleles $^{1}$ & Reference \\
\hline CSN1S1 & Allele-specific PCR & $E$, non $E$ & Jansà-Pérez et al., 1994; Rando et al., 1998 \\
& PCR-RFLP & 01, non 01 & Sztankoova et al., 2006 \\
CSN2 & Allele-specific PCR & $A^{*}, F$ & Ramunno et al., 2000 \\
& Light cycler analysis & $A, C$ & Ramunno et al., 1995 \\
CSN1S2 & PCR-RFLP & $D, F, N^{*}, 0$ & Stankoova et al., 2008 \\
CSN3 & Primer extension analysis & $A, B, C, D, E, F, G$ & Ramunno et al., 2001a,b \\
\hline
\end{tabular}

${ }^{1} A^{*}=A, B, C, D ; N^{*}=A, B, C, E$.

Selection and controlled mating are used to produce breeding stock that is distributed to other breeders.

The WSH breed was developed between 1900 and 1930, mainly in Moravian regions, through the crossbreeding of local goats with Saanen bucks imported from Switzerland to improve milk production. The WSH is classified as being part of the Saanen group. The typical dairy performance in a 280-d lactation period is 680 to $800 \mathrm{~kg}$ of milk with $3.3 \%$ fat and $2.9 \%$ protein (Bucek et al., 2007). About half of the purebred population is kept in individual households (1-3 dams), with performance recorded and selection applied according to the breeding objective of the breeders' association. These dams are mothers of breeding sires sold to large commercial dairy herds (50-500 dams), which then produce their own replacements. Commercial herds are mainly stall-fed, with year-round housing and little or no grazing.

The BSH is classified in the Chamois group. From the period of about 1900 to 1960, colored local goats of North Bohemia were improved through crossbreeding with German (Harz) and Swiss (brown Alpine) bucks. The average lactation time is $280 \mathrm{~d}$ and milk yield is 780 to $900 \mathrm{~kg}$ with $3.5 \%$ fat and $3 \%$ protein (Bucek et al., 2007). Commercial herds are smaller than for WSH (15-70 dams) and use mainly seasonal grazing. At present, only natural mating is used, either by individual mating or by allotting bucks to a group of dams. Inbreeding is avoided for at least 3 generations.

For the haplotype assay, we used trio families consisting of parents and offspring of WSH (together we evaluated 41 families) and BSH (44 families). Animals were reared in $7(\mathrm{WSH})$ and $10(\mathrm{BSH})$ herds, and 6 (WSH) and 15 (BSH) breeders were involved in the study. All tested breeders (21 total) were used in the almost entire population of genetic resources of both goat breeds kept in 17 herds between the years 2000 and 2004.

Genotyping analyses were based on blood samples ( $\mathrm{n}=123 \mathrm{WSH}$ and $132 \mathrm{BSH}$ ). Genomic DNA was extracted from blood using ABI Prism 6100 analysis (Applied Biosystems, Foster City, CA) by the standard protocol. Genotyping at the calcium-sensitive casein loci (CSN1S1, CSN2, and CSN1S2) and CSN3 was performed with various methods (Table 1). The amplification products and the restriction patterns were visualized on agarose gels (PCR-agarose, Top-Bio Ltd., Praha, Czech Republic) in Tris-borate EDTA buffer stained with ethidium bromide.

PowerMarker software (version 3.25, Bioinformatics Research Center, North Carolina State University, Raleigh; Liu and Muse, 2005) was used to determine allele frequencies, heterozygosity, gene diversity, and PIC (Botstein et al., 1980) and to verify Hardy-Weinberg equilibrium. Haplotype frequencies for trio families were estimated by the EM algorithm implemented in PowerMarker (Rohde and Fuerst, 2001), considering only alleles with frequencies $>0.05$. Predicted haplotype frequencies in $41 \mathrm{WSH}$ and in $44 \mathrm{BSH}$ trio families were calculated separately (based on 2 data sets). Overall frequencies of the haplotypes were calculated as predicted (expectation maximization algorithm) frequencies based on genotype data of all animals in 85 trio families of both breeds.

At the CSN1S1 locus, allele $F$ was predominant in both breeds $(F=0.789$, WSH; $F=0.701$, BSH). Allele $A^{*}(A, B, C$, and $D$ alleles $)$ occurred with lower frequency $\left(A^{*}=0.203\right.$, WSH; $A^{*}=0.258$, BSH). Alleles $E$ and 01 were rare in both breeds $(E=0.004, \mathrm{WSH}$; $E=0.042, \mathrm{BSH})$ and the 01 allele $(01=0.004, \mathrm{WSH})$ was not observed in the BSH breed. Frequencies were similar to the Swiss breeds Alpine and Saanen, with a high frequency of the $F$ allele relative to French and Spanish breeds (Jordana et al., 1996; Tadlaoui Ouafiet al., 2002; Marletta et al., 2005).

At the CSN2 locus, 2 alleles, $A$ and $C$, were detected. In both breeds, allele $C$ was predominant $(C=0.774$, WSH; $C=0.603, \mathrm{BSH})$ compared with allele $A(A=$ 0.227 , WSH; $A=0.397, \mathrm{BSH}$ ). Similar results were described in Italian populations, especially in Saanen and Camosciata (Chessa et al., 2005; Caroli et al., 2006, 2007). No null alleles were observed, in agreement with the results obtained in other breeds (Marletta et al., 2005; Sacchi et al., 2005; Caroli et al., 2006).

At the CSN1S2 locus, allele $F$ was predominant ( $F$ $=0.735)$ in the WSH, whereas $N^{*}(A, B, C$, and $E$ 
Table 2. Data analyses ${ }^{1}$ at the CSN1S1, CSN1S2, CSN2, and CSN3 loci in the White Shorthaired (WSH) and Brown Shorthaired (BSH) goats

\begin{tabular}{|c|c|c|c|c|c|c|}
\hline Marker & $\mathrm{H}_{\mathrm{obs}}$ & $\mathrm{H}_{\exp }$ & $\mathrm{PIC}^{2}$ & Chi-square & $\mathrm{df}^{3}$ & $P$-value \\
\hline \multicolumn{7}{|l|}{ WSH } \\
\hline$C S N 1 S 1$ & 0.423 & 0.337 & 0.285 & 8.837 & 6 & 0.183 \\
\hline$C S N 2$ & 0.423 & 0.352 & 0.289 & 5.031 & 1 & $0.025^{*}$ \\
\hline$C S N 1 S 2$ & 0.349 & 0.389 & 0.313 & 1.252 & 1 & 0.263 \\
\hline$C S N 3$ & 0.634 & 0.587 & 0.517 & 39.290 & 3 & $1.51 \mathrm{E}-08^{* * *}$ \\
\hline \multicolumn{7}{|l|}{$\mathrm{BSH}$} \\
\hline$C S N 1 S 1$ & 0.598 & 0.441 & 0.373 & 24.070 & 3 & $2.41 \mathrm{E}-0.5$ \\
\hline$C S N 2$ & 0.598 & 0.479 & 0.364 & 8.199 & 1 & $0.004^{* *}$ \\
\hline$C S N 1 S 2$ & 0.522 & 0.456 & 0.352 & 2.792 & 1 & 0.095 \\
\hline$C S N 3$ & 0.667 & 0.601 & 0.516 & 2.077 & 3 & 0.166 \\
\hline
\end{tabular}

${ }^{1} \mathrm{H}_{\mathrm{obs}}=$ observed heterozygosity; $\mathrm{H}_{\exp }=$ expected heterozygosity.

${ }^{2}$ Polymorphic information content; Botstein et al. (1980)

${ }^{3} \mathrm{df}=\mathrm{a}-1$, where $\mathrm{a}$ is the number of alleles.

${ }^{*} 0.01<P \leq 0.05 ;{ }^{* *} 0.001<P \leq 0.01 ;{ }^{* * *} P \leq 0.001$.

alleles) occurred with a frequency of 0.265 . Allele $N^{*}$ was predominant in the BSH breed $\left(N^{*}=0.648\right.$ vs. 0.352 for $F$ ). Ramunno et al. (2001a) identified the $F$ allele as being associated with a normal or high level of $\alpha_{S^{2}}$-casein content. The gene test for the $F$ allele discriminated only between this allele and the $N^{*}$ allele, a group of alleles associated with an increased $\alpha_{\mathrm{S}^{2}}$-casein content. Neither the intermediate $D$ nor null alleles were observed, similar to Italian breeds (Marletta et al., 2005; Sacchi et al., 2005; Caroli et al., 2006).

Allele $B$ was the most common $C S N 3$ allele in the WSH breed $(B=0.553)$, followed by $A(A=0.284)$. However, $A(0.443)$ and $B(0.432)$ alleles had similar frequencies in the BSH breed. Allele $C$ had a very low frequency $(C=0.163)$ in the WSH breed and was absent in the BSH breed. By contrast, allele $D$ was absent in the WSH breed and had a low frequency $(D=0.125)$ in the BSH breed. These results are compatible with those in other European, Middle Eastern, and African breeds (Sacchi et al., 2005; Caroli et al., 2006, 2007; Edghard et al., 2007).

According to Hardy-Weinberg law, the WSH breed was in genetic equilibrium at the 2 loci CSN2 and CSN3 ( $P \leq 0.05$ and $P \leq 0.001$, respectively). The $\mathrm{BSH}$ breed was in genetic equilibrium at the CSN2 locus only $(0.001<P \leq 0.01$; Table 2$)$. Observed and expected heterozygosity and PIC in both goat breeds were calculated. The PIC showed a small or medium value for an individual locus compared with the mean PIC value of all loci in both populations (Table 2; data not shown).

The Hardy-Weinberg equilibrium results and the PIC without presentation of phenotypic data give only the basic information about genetic diversity in selected loci. In this case, they can indicate possible problems in the casein loci (e.g., reduction of genetic diversity or reduction of polymorphisms and heterozygosity) in populations of goats included in genetic resources.
Haplotype frequencies at the casein cluster were estimated for the 41 and 44 trio families under the assumption of allelic association based on all genotype combinations found using expectation maximization algorithm software (Rohde and Fuerst, 2001).

Twenty-three different genotypes were observed in the WSH goat population, with (CSN1S1-CSN2CSN1S2-CSN3) FFCCFFAC (21.5\%), FA*ACFN ${ }^{*} A B$ $(12 \%)$, and $F A^{*} A C F N^{*} B B(11.1 \%)$ being the most common. The BSH goat population had 29 different genotypes, with $F F A C F N^{*} A B(10 \%), F A^{*} A C N^{*} N^{*} B D$ $(8.6 \%), \quad F A^{*} A C F N^{*} A B(7.9 \%)$, and $F F A C F N^{*} A A$ (7.1\%) being the most common. Following haplotype reconstruction, 22 different plausible haplotypes were observed overall in the Czech national goat population. According to breed, 5 (WSH) and 6 (BSH) haplotypes were observed with frequencies $>0.05$ (Table 3). High linkage disequilibrium was found in both breeds as indicated by the chi-square test for association performed with the expectation maximization algorithm. Estimated frequencies of the most common haplotypes (frequencies $>0.05$ ) are shown in Table 3. The most common haplotype in the WSH population was $F C F B$ (CSN1S1-CSN2-CSN1S2-CSN3), with a frequency of 0.261 . The haplotype FCFA (0.218) was the most common in the BSH population. The 2 next most common haplotypes in the WSH population, FCFA and FCFC, and 4 haplotypes in the BSH population, $F A N^{*} B$, $F A N^{*} A, A C N^{*} D$, and $F C N^{*} B$, occurred at a percentage incidence of approximately 11 to $23 \%$ (Table 3 ). In our work, we also identified the CSN3 $D$ allele, which is associated with CSN1S1 F and with CSN1S1 $A^{*}$ as described by Sacchi et al. (2005).

The haplotype frequencies were similar to those described by Caroli et al. (2006) and Sacchi et al. (2005) for some Italian goat breeds. Differences in the distribution of the casein haplotypes may be a consequence of the breed's geographic origin and genetic drift or the 
Table 3. Haplotype frequencies ${ }^{1}$ at the casein loci in the White Shorthaired (WSH) and Brown Shorthaired (WSH) goat populations ${ }^{2}$

\begin{tabular}{|c|c|c|c|c|c|c|}
\hline \multicolumn{4}{|c|}{ Casein loci ${ }^{3}$} & \multirow[b]{2}{*}{ WSH $(\mathrm{n}=41)$} & \multirow[b]{2}{*}{$\mathrm{BSH}(\mathrm{n}=44)$} & \multirow[b]{2}{*}{ Overall } \\
\hline$C S N 1 S 1$ & CSN2 & $C S N 1 S 2$ & $C S N 3$ & & & \\
\hline$A^{*}$ & $A$ & $F$ & $B$ & 0.049 & 0.006 & 0.027 \\
\hline$A^{*}$ & $A$ & $N^{*}$ & $A$ & 0.048 & 0.043 & 0.046 \\
\hline$A^{*}$ & $A$ & $N^{*}$ & $B$ & 0.080 & 0.023 & 0.060 \\
\hline$A^{*}$ & $C$ & $F$ & $A$ & 0.006 & 0.022 & 0.012 \\
\hline$A^{*}$ & $C$ & $F$ & $B$ & -5 & 0.017 & 0.002 \\
\hline$A^{*}$ & $C$ & $N^{*}$ & $A$ & - & 0.007 & 0.003 \\
\hline$A^{*}$ & $C$ & $N^{*}$ & $B$ & 0.012 & 0.048 & 0.030 \\
\hline$A^{*}$ & $C$ & $N^{*}$ & $D$ & - & 0.113 & 0.057 \\
\hline$E$ & $A$ & $F$ & $B$ & - & 0.006 & 0.005 \\
\hline$E$ & $A$ & $N^{*}$ & $A$ & - & 0.006 & 0.003 \\
\hline$E$ & $A$ & $N^{*}$ & $B$ & 0.006 & 0.023 & 0.013 \\
\hline$F$ & $A$ & $F$ & $A$ & 0.024 & 0.018 & 0.019 \\
\hline$F$ & $A$ & $F$ & $B$ & 0.006 & 0.006 & 0.004 \\
\hline$F$ & $A$ & $N^{*}$ & $A$ & - & 0.124 & 0.068 \\
\hline$F$ & $A$ & $N^{*}$ & $B$ & 0.024 & 0.138 & 0.072 \\
\hline$F$ & $A$ & $N^{*}$ & $D$ & - & 0.006 & 0.003 \\
\hline$F$ & $C$ & $F$ & $A$ & 0.233 & 0.218 & 0.224 \\
\hline$F$ & $C$ & $F$ & $B$ & 0.261 & 0.054 & 0.165 \\
\hline$F$ & $C$ & $F$ & $C$ & 0.158 & - & 0.076 \\
\hline$F$ & $C$ & $N^{*}$ & $B$ & 0.086 & 0.112 & 0.098 \\
\hline$F$ & $C$ & $N^{*}$ & $D$ & - & 0.012 & 0.007 \\
\hline 01 & $C$ & $F$ & $B$ & 0.006 & - & 0.003 \\
\hline
\end{tabular}

${ }^{1}$ Haplotypes with frequencies greater than 0.05 in either the WSH or BSH breeds are in bold.

${ }^{2} \mathrm{n}=$ numbers of trio families.

${ }^{3} A^{*}=A, B, C, D ; N^{*}=A, B, C, E$.

${ }^{4}$ Overall frequencies of the haplotypes are calculated as predicted (expectation maximization algorithm) frequencies based on genotype data of all animals in 85 trio families of both breeds.

${ }^{5}-=0.000$.

selection strategy of breeds, or it may have originated from recent mutations or recombination within haplotypes, as well as random sampling of animals tested. The high frequency of the casein haplotypes FCFA and $F C F B$ in the Czech national population may be the consequence of genetic drift or of using parental lines in specific breeding as well as a recombination event.

Based on our results, the determined genetic polymorphism of the $\alpha_{S_{1}}$-casein in both Czech goat populations corresponds to the 4 previously described groups of the $\alpha_{S 1}$-casein synthesis level. All alleles identified at other casein loci ( $\beta$-casein and $\alpha_{\mathrm{S}_{2}}$-casein) correspond to a normal-rate protein synthesis group, according to Rando et al. (2000). The connection between the calcium-sensitive haplotypes described by Rando et al. (2000) and the frequencies of the haplotypes considered in our work is shown in Table 4 . The first 8 haplotypes of Table 3 correspond to haplotype I of Table 4. This haplotype is characterized by the occurrence of strong alleles at $C S N 1 S 1\left(A, B_{1}, B_{2}, B_{3}, B_{4}, C, H, L\right.$, and $M$, producing almost $3.5 \mathrm{~g} / \mathrm{L}$ of $\alpha_{\mathrm{S} 1}$-casein each) and alleles with normal synthesis levels at CSN2 $(A, B$, and $C$, producing $5 \mathrm{~g} / \mathrm{L}$ of $\beta$-casein each) and $C S N 1 S 2$ ( $A, B$, $C, E, F$, and $G$, producing $2 \mathrm{~g} / \mathrm{L}$ of $\alpha_{\mathrm{s} 2}$-casein each). Moreover, $E A F$ and $E A N^{*}$ match with haplotype III, which is characterized by the occurrence of intermediate alleles at $\alpha_{\mathrm{S} 1}$-casein $(E$ and $I, 1.1 \mathrm{~g} / \mathrm{L})$ and normal alleles at CSN2 and CSN1S2. Haplotypes FAF, FAN*, and $F C F$ match with haplotype IV (weak alleles $F$ or $G$ at CSN1S1, $0.45 \mathrm{~g} / \mathrm{L}$, and normal alleles at CSN2 and CSN1S2) and haplotype $01 C F$ corresponds to haplotype VI (evidence null alleles 01, 02, and $N$ at CSN1S1 and normal alleles at CSN2 and CSN1S2). In this study, the most frequent haplotype was IV, with an incidence percentage of about $80 \%$ (WSH) and $69 \%$ (BSH); consequently, low-rate casein synthesis could be expected in both breeds.

Table 4. Frequencies of the calcium-sensitive casein haplotype on the basis of casein level by Rando et al. (2000) in the Czech White Shorthaired (WSH) and Brown Shorthaired (BSH) goat populations ${ }^{1}$

\begin{tabular}{|c|c|c|c|}
\hline \multirow{2}{*}{$\begin{array}{l}\text { Quantitative } \\
\text { haplotype }\end{array}$} & \multirow{2}{*}{$\begin{array}{c}\text { Total protein } \\
(\mathrm{g} / \mathrm{L})\end{array}$} & \multicolumn{2}{|c|}{ Frequency } \\
\hline & & WSH $(\mathrm{n}=41)$ & $\mathrm{BSH}(\mathrm{n}=44)$ \\
\hline I & 10.5 & 0.195 & 0.333 \\
\hline III & 8.1 & 0.006 & 0.034 \\
\hline IV & 7.5 & 0.792 & 0.687 \\
\hline VI & 7.0 & 0.006 & 0.000 \\
\hline
\end{tabular}

${ }^{1} \mathrm{n}=$ numbers of trio families. 
Caroli et al. (2006) postulated that haplotypes FCFA, $F C F B$, and $F C A B$ correspond to the 1 of 2 possible evolutionary lineages of the casein haplotype. On the basis of these results and haplotypes (FCFA, FCFB, FCFC, and $F C N^{*} B$ ) that occurred in the Czech national goat population, we assume that the given haplotypes could be ancestral for the European goat populations or may be typical for goat populations related to or originated from the Saanen breeds. This result indicates a necessity for continued research on the distribution of haplotypes in other European goat breeds to compare results and confirm the real ancestral haplotype pattern.

Future candidate genes are needed for more precise genetic characterization, which could be used in breeding schemes aimed at the improvement of the quality of processed milk and cheese yields of the Czech dairy goat breeds, as well as in developing a specific program that helps to preserve the existing biodiversity through the cryoconservation of both typical and unusual genotypes for future use.

\section{ACKNOWLEDGMENTS}

This project was supported by the Department of Agriculture and National Agriculture Research Programme of the Czech Republic, Prague (MZE0002701404 and NAZV 1G57051).

\section{REFERENCES}

Boettcher, P. J., A. Caroli, A. Stella, S. Chessa, E. Budelli, and F. Canavesi. 2004. Effects of casein haplotypes on milk production traits in Italian Holstein and Brown Swiss cattle. J. Dairy Sci. 87:4311-4317.

Botstein, D., R. L. White, M. Skolnick, and R. W. Davis. 1980. Construction of a genetic linkage map in man using restriction fragment length polymorphism. Am. J. Hum. Genet. 32:314331 .

Bucek, P., J. Pytloun, M. Kolbl, M. Milerski, A. Pindak, V. Mares, R. Konrad, P. Rubasova, V. Skaryd, J. Kuchtik, P. Sokol, and B. Janstova. 2007. Ročenka chovu ovcí a koz v České republice za rok 2006 [Sheep and goat breeding year book 2006]. Českomoravská společnost chovatelů, a.s. U Topiren 2/860, Prague, Czech Republic.

Caroli, A., F. Chiatti, S. Chessa, D. Rignanese, P. Bolla, and G. Pagnacco. 2006. Focusing on the goat casein complex. J. Dairy Sci. 89:3178-3187.

Caroli, A., F. Chiatti, S. Chessa, D. Rignanese, E. M. IbeaghaAwemu, and G. Erhardt. 2007. Characterization of the casein gene complex in West Africa goats and description of a new $\alpha_{\mathrm{S}_{1}}$-casein polymorphism. J. Dairy Sci. 90:2989-2996.

Chessa, S., E. Budelli, F. Chiatti, A. M. Cito, P. Bolla, and A. Caroli. 2005. Short communication: Predominance of $\beta$-casein (CSN2) C allele in goat breeds reared in Italy. J. Dairy Sci. 88:1878-1881.

Hayes, H., E. Petit, C. Bouniol, and P. Popescu. 1993. Localization of the alpha-s2-casein gene (CASAS2) to the homologous cattle, sheep and goat chromosome 4 by in situ hybridization. Cytogenet. Cell Genet. 64:282-285.

Hinnes, H. C., G. F. W. Haenlein, J. P. Zikakis, and H. C. Dickey. 1977. Blood antigen, serum protein, and milk protein gene frequencies and genetic interrelationships in Holstein cattle. J. Dairy Sci. 60:1143-1151.

Jansà-Pérez, M. J., C. Lerox, A. S. Bonastre, and P. Martin. 1994. Occurrence of a LINE sequence in the $3^{\prime} \mathrm{UTR}$ of the goat alpha $\mathrm{s}^{-}$ casein E-encoding allele associated with reduced protein synthesis level. Gene 147:179-187.

Jordana, J., M. Amills, E. Díaz, C. Angulo, J. M. Serradilla, and A. Sanchez. 1996. Gene frequencies of caprine $\alpha_{\mathrm{S} 1}$-casein polymorphism in Spanish goat breeds. Small Rumin. Res. 20:215-221.

Lien, S., and S. Rogne. 1993. Bovine casein haplotypes: Number, frequencies and applicability as genetic markers. Anim. Genet. 24:373-376.

Liu, K., and V. Muse. 2005. PowerMarker: Integrated analysis environment for genetic marker data. Bioinformatics 21:2128 2129 .

Marletta, D., S. Bordonaro, A. M. Guastella, A. Criscione, and G. D'Urso. 2005. Genetic polymorphism of the calcium sensitive caseins in Sicilian Girgentana and Argentata dell'Etna goat breeds. Small Rumin. Res. 57:133-139.

Meuwissen, T. H. E., and M. E. Goddard. 1996. The use of marker haplotypes in animal breeding schemes. Genet. Sel. Evol. 28:161176 .

Oklahoma State University. Breeds of livestock. http://ansi.okstate. edu/breeds/goats/ Accessed Feb. 22, 1995.

Ramunno, L., G. Cosenza, M. Pappalardo, E. Longobardi, D. Gallo, N. Pastore, P. Di Gregorio, and A. Rando. 2001a. Characterization of two new alleles at the goat CSN1S2 locus. Anim. Genet. $32: 264-268$.

Ramunno, L., G. Cosenza, M. Pappalardo, N. Pastore, D. Gallo, P. Di Gregorio, and P. Masina. 2000. Identification of the goat CSN1S1 F allele by means of PCR-RFLP. Anim. Genet. 31:333-346.

Ramunno, L., E. Longobardi, M. Pappalardo, P. Di Gregorio, G. Cosenza, P. Mariani, N. Pastore, and P. Masina. 2001b. An allele associated with a no detectable amount of ${\alpha \mathrm{s}_{2}}_{2}$ casein in goat milk. Anim. Genet. 32:19-26.

Ramunno, L., P. Mariani, M. Pappalardo, A. Rando, M. Capuano, P. Di Gregorio, and G. Cosenza. 1995. Un gene effetto maggiori sul contento di casein b nel latte di capra. Pages 185-186 in XI Congresso ASPA. Grado, Italy, June 19-22, 1995. Università degli Sudi di Udine, Udine, Italy.

Rando, A., P. Di Gregorio, L. Ramunno, P. Mariani, A. Fiorella, C. Senesse, D. Marleta, and P. Masina. 1998. Characterization of the $\mathrm{CSN}_{1 \mathrm{~A}}^{\mathrm{G}}$ allele of the goat $\alpha_{\mathrm{s} 1}$-caein locus by the insertion of a relict of a long interspersed element. J. Dairy Sci. 81:1735-1742.

Rando, A., L. Ramunno, and P. Masina. 2000. Mutations in casein genes. Zoot. Nutriz. Anim. 26:105-114.

Rijnkels, M., M. Kooiman, H. A. De Boer, and F. R. Pieper. 1997. Organization of the bovine casein gene locus. Mamm. Genome $8: 148-152$

Rohde, K., and R. Fuerst. 2001. Haplotyping and estimation of haplotype frequencies for closely linked biallelic multilocus genetic phenotypes including nuclear family information. Hum. Mutat. 17:289-295.

Sacchi, P., S. Chessa, E. Budelli, P. Bolla, G. Ceriotti, and D. Soglia. 2005. Casein haplotype structure in five Italian goat breeds. J. Dairy Sci. 88:1561-1568.

Sztankoova, Z., T. Kott, V. Czernekova, G. Dudkova, V. Matlova, and J. Soldat. 2006. Technical note: A new allele-specific polymerase chain reaction method (AS-PCR) for detection of the goat CSN1S1 (01) allele. Small Rumin. Res. 66:282-285.

Sztankoova, Z. J., T. Kysel'ova, Kott, and E. Kottova. 2008. Technical note: Detection of the $\mathrm{C}$ allele of $\beta$-casein (CSN2) in Czech dairy goat breeds using LightCycler analysis. J. Dairy Sci. 91:1-5.

Tadlaoui Ouafi, A., J. M. Babilliot, C. Perouc, and P. Martin. 2002. Genetic diversity of two main Moroccan goat breeds: Phylogenetic relationship with four breeds reared in France. Small Rumin. Res. $45: 225-233$.

Threadgill, D. W., and J. E. Womack. 1990. Genomic analysis of the major bovine milk proteins genes. Nucleic Acids Res. 18:6935-6942.

Velmala, R., J. Vilkk, K. Elo, and A. Maki-Tanila. 1995. Casein haplotypes and their association with milk production traits in the Finnish Ayrshire cattle. Anim. Genet. 26:419-425.

Yahyaoui, M. H., A. Angiolillo, F. Pilla, A. Sanchez, and J. M. Folch. 2003. Characterization and genotyping of the Caprine $\kappa$-casein variants. J. Dairy Sci. 86:2715-2720. 